\title{
Maternal health care service utilization in post-war Liberia: analysis of nationally representative cross-sectional household surveys
}

Sanni Yaya ${ }^{1 *}$ (D), Olalekan A. Uthman², Ghose Bishwajit ${ }^{1}$ and Michael Ekholuenetale ${ }^{3}$

\begin{abstract}
Background: Post-war Liberia has a fast-growing population and an alarming maternal mortality ratio (MMR). To provide a better understanding about healthcare system recovery in post-war country, we explored the changes in maternal healthcare services utilization between 2007 and 2016.

Methods: We used 2007 and 2013 Liberia Demographic and Health Survey (LDHS) and the 2016 Malaria Indicator Survey (MIS) in this study. The outcomes of interest were: place of delivery and antenatal care visits. Univariate analysis was conducted using percentages and means (standard deviations) and multiple binary multivariable logistic models were used to examine the factors associated with the outcome variables.

Results: Between 2007 and 2016, the percentage of adequate ANC visits increased from 71.20 to 79.8\%, and that of facility-based delivery increased from 40.90 to $74.60 \%$. The odds of attending at least four ANC visits and formal institutional delivery were low among women residing in rural area, but high among women with higher education, used electronic media, and lived in high wealth index households. Additionally, attending ANC at least four times increased the odds of facility-based delivery by almost threefold.

Conclusion: The findings suggest that key maternal healthcare utilization indicators have improved substantially, especially facility-based delivery. However, a large proportion of women remain deprived of these life-saving health services in the post-war era. Greater healthcare efforts are needed to improve the quality and coverage of maternal healthcare in order to enhance maternal survival in Liberia.
\end{abstract}

Keywords: Liberia, Post-war era, Maternal healthcare service utilization, Antenatal care, Facility-based delivery

\section{Background}

Globally, over $90 \%$ of maternal and child mortalities occur in developing countries, with the most vulnerable populations sharing the greatest burden of the mortality from preventable causes $[1,2]$. No or inadequate access to maternal healthcare services increases the risks of a range of pregnancy and obstetric complications that can result in higher rates of maternal morbidity and mortality that in turn lowers the chances of child survival. In Africa, health care system has not satisfactorily met the

\footnotetext{
* Correspondence: sanni.yaya@uOttawa.ca

${ }^{1}$ School of International Development and Global Studies, University of

Ottawa, Ottawa, Canada

Full list of author information is available at the end of the article
}

healthcare needs of women. Maternal mortality in sub-Saharan region has remained unacceptably high, recording over 510 in maternal mortality cases per 100,000 live births [3]. For decades, there has been increasing interest in the provision and accessibility to maternal health care services in developing countries, particularly in those emerging from long years of civil war, such as Liberia. The interest is to make concerted efforts in reducing maternal and neonatal mortality, which has recorded persistent high prevalence [1].

Liberia ended 14 years of civil war in 2003. In the course of the war, the health care system was devastated where preponderance health facilities were rendered ineffective, which has made the country to account for

(c) The Author(s). 2019 Open Access This article is distributed under the terms of the Creative Commons Attribution 4.0 International License (http://creativecommons.org/licenses/by/4.0/), which permits unrestricted use, distribution, and 
some of the poorest health outcomes. This large breakdown in the health system brought increased dependence on alternative health care services, such as traditional healers amongst others [4]. A remarkable event of the two consecutive Liberian civil wars (between 1989 and 1996 and 1997-2003 respectively) is the deterioration of the country's health system care system [5]. Liberia is currently identified among the countries in the world with the highest maternal mortality ratios, with an alarming rate of over 725 deaths per 100,000 live births [6]. Although the neonatal, infant and under-five mortality have reportedly declined over the past decade, the rates are still very high for infants (54 deaths per 1000 live births) and under-five children (approximately 1 in 11 children) [7]. These indicators place Liberia among the sub-Saharan African countries with highest maternal and neonatal mortality rates. Like other post-war countries, health care system in Liberia faces a multitude of supply side barriers such as inadequate infrastructure, lack of skilled health personnel, and medical equipment [8]. Low utilization of contraceptive methods and high teenage pregnancies are prominent contributors to maternal death, as approximately $60 \%$ of neonatal deaths occur among adolescent women compared to about $6 \%$ for those above 19 years, which indicates the need to delay child birth through access to improved sexual and reproductive health care services [9]. The health sector has made continuous efforts to enhance overall access to health services in Liberia. In 2007, Liberian government initiated a widespread effort to prioritize access to basic health care and rebuild the health care system [10]. Basic Package of Health Services (BPHS) was constructed as cost-effective and evidence-based interventions, necessary to improve maternal health by identifying high-priority services in health care facilities [11]. This approach was adopted in other post-war countries, such as Afghanistan, Sierra Leone and South Sudan, and has been recognized with increasing access to health care and reduction morbidity and mortality [12-15]. A previous study showed that, less than $50 \%$ of all deliveries in Liberia were conducted by a skilled birth attendant, with a large disparity by geographical locations. The least skilled birth attendance was in the northern central region of the country [16].

Currently, there are serious demand side constraints, such as misconceptions or wrong perception, lack of awareness or knowledge and harmful socio-cultural norms in the provision of and accessing maternal healthcare services especially for the socioeconomically disadvantaged populations. The National Drug Service (NDS) is yet to meet required operational standard, notwithstanding an overall overhaul is in progress especially in delivery of necessary RMNCAH services. This approach is an essential component of Liberia's plans and policies to achieve the Sustainable Development Goals (SDGs), particularly goals 3 and 5 by year 2030 [17]. It also states the country's efforts in line with United Nation's scheme of Every Woman, Every Child initiative to drastically reduce maternal and child mortality from preventable causes, as contained in the regulatory framework $[9,18]$.

The RMNCAH framework centers on sustainable health outcomes, based on the principles of promoting equity and gender equality, ownership of the health system at national levels, respect for reproductive health rights, equality in access to health care utilization and ensuring a responsive health system to patients' needs. The major approach to optimize efficiency in health care delivery is linked to enhanced accountability through improved productivity, performance incentives and integrating RMNCAH service delivery with other health care programs, such as malaria, tuberculosis, HIV amongst others [18]. In this paper, our goal is to explore the determinants of changes in maternal services utilization by deprived groups in post-conflict settings.

\section{Methods}

\section{Data source}

Datasets used in this study were obtained from the 2007 and 2013 rounds of Liberia Demographic and Health Surveys (LDHS) and 2016 Malaria Indicator Survey (MIS). Questionnaire for individual women aged 15-49 was used to obtain nationally representative sample respondents. The population-based surveys were commissioned by USAID and carried out by the Liberia government, with operational support from ICF International. The surveys employ stratified two-stage cluster design. Clusters or Enumeration Areas (EA) were first selected from recent population census sample frame and households were systematically selected from the clusters. The surveys used standardized questionnaires developed by the MEASURE DHS programme particularly for households, men and women these are administered during face-to-face interviews. The response rates were above $95 \%$ for each survey; as such it was unnecessary to conduct weighting prior to data analysis. Details of survey procedures can be found elsewhere $[6,19]$.

\section{Study sample}

The data for this study was extracted from the Liberia population-based surveys for the years 2007, 2013 and 2016. The individual women datasets were used in the analysis; these consisted of large representative samples of women aged 15-49 years. Data from 7092 women in 
2007, 9239 women in 2013, 4290 women in 2016 were analyzed in this study.

\section{Variables measurement and conceptual framework}

The main outcome variables are ANC visits and place of delivery. The number of ANC visits is the self-reported frequency of skilled care attention or treatment received during pregnancy. Also, the place of delivery is used to identify where childbirth occurred, this was in dichotomous forms; whether at respondents' home/other traditional homes or at a health facility. In addition, two groups of independent variables were used, namely; background and maternal characteristics. The selection of explanatory variables was based on the conceptual framework by Ejembi et al. [20]. The contextual factors implicitly influence maternal sexual and reproductive health care by acting on the individual and household factors at various levels to influence women's health care service utilization. The background characteristics included maternal age (measured in the interval; 15-19, $20-24,25-29,30-34,35-39,40-44$ and 45-49), region, place of residence (whether urban or rural), education (including women with no formal education, up to those with higher education), religion, sex of household head and wealth index. The wealth index was constructed using household asset data, such as ownership of items including; source of drinking water, sanitation facilities, television, bicycle, car and type of flooring material. DHS used information on household assets to create an index that is used to represent the wealth of the households $[6,20,21]$. The proximate characteristics were age at first birth, children ever born and maternal frequency of reading newspaper or magazine, listening to radio and watching television.

\section{Data analysis}

In this paper, we used univariate analysis to summarize respondents' characteristics from the three rounds of the data sets using percentages and mean (and standard deviations). To adjust for complex survey design, we used the survey module (svyset) for all analyses to account for clustering, stratification and sample weight. Correlation matrix was used to conduct multicollinearity diagnostics to identify interdependence between explanatory variables using a cut-off of 0.6 [22]. Hence, all explanatory variables were retained for analysis due to lack of collinearity. In addition, Mckelvey and Zavoinas model fitness was presented [23]. the trend of maternal health care in post-war era was presented in chart. We fitted the unadjusted and adjusted binary logistic regression models to assess significant factors of facility-based delivery and antenatal care visits. Measures above 1 signified a higher likelihood of maternal healthcare use, and measures less than 1 means a lower likelihood of maternal healthcare use. Statistical significance was set at 5\%, and analyses were conducted using Stata version 14.0 (Statacorp, College Station, Texas, United States of America).

\section{Ethical considerations}

We did the analyses using publicly available data from demographic health surveys. Ethical procedures were the responsibility of the institutions that commissioned, funded, or managed the surveys. All DHS surveys are approved by ICF international as well as an Institutional Review Board (IRB) in respective country to ensure that the protocols follow the U.S. Department of Health and Human Services regulations for the protection of human subjects.

\section{Results}

\section{Study participant characteristics}

Results presented in Table 1 showed the summary statistics of the characteristics of respondents from 2007, 2013 and 2016 surveys. The mean age (SD) of respondents was approximately $29(9.0)$ years. Also, the mean age (SD) at first birth was 18(3.0) years for the surveys. For age interval, respondents aged 40-44 and 45-49 years were least represented below one-tenth each. While participants ages; $15-19,20-24$ and $25-29$ years were almost equally represented about $20 \%$ each. In 2007, majority of respondents were from Morovia, followed by North Central region, but in 2013, about $30 \%$ of the respondents were from South Central and followed by North central. In 2016, vast respondents were majorly from Morovia. This shows that Morovia is largely populated which proportionately led to more selection of respondents compared to other regions. Furthermore, the highest proportion of respondents from urban place of residence was $54.3 \%$. This indicates that about half of respondents are rural dwellers. About $40 \%$ of participants have no formal education; up to $30 \%$ have only primary education. The trend (2007-2016) showed that approximately one-third have at least secondary education. On religious beliefs, about $88 \%$ are Christians, and $10 \%$ are Muslims. The economic status of the respondents was measured using the wealth index, this revealed that a maximum of $52 \%$ are below middle class, while less than half was ever above middle class. See Table 1 for details.

\section{Changes in maternal services utilization}

The trend of facility-based delivery showed a maximum of three-quarters in the post-war era. Figure 1 indicated $33 \%$ increase in a decade. However, ANC visits at least 4 showed a weak change in a decade, starting from $71.2 \%$ in 2007, to $76.1 \%$ in 2013 and now to $79.8 \%$ in 2016 . Only $8.6 \%$ increase in a decade. The trend in 
Table 1 Characteristics of respondents, Liberia, 2007-2016

\begin{tabular}{|c|c|c|c|}
\hline Variable, \%(95\% Cl) & 2007 DHS $(n=7092)$ & 2013 DHS $(n=9239)$ & $2016 \operatorname{MIS}(n=4290)$ \\
\hline Mean age (SD) & $29.2(9.6)$ & $29.2(9.8)$ & $28.7(9.4)$ \\
\hline Mean age at first birth (SD) & $18.6(3.7)$ & $18.2(3.4)$ & No data \\
\hline \multicolumn{4}{|l|}{ Age } \\
\hline $15-19$ & $18.9(18.0-19.8)$ & $20.7(19.9-21.6)$ & $20.9(19.7-22.1)$ \\
\hline $20-24$ & $19.5(18.6-20.5)$ & $17.1(16.4-17.9)$ & $18.6(17.5-19.8)$ \\
\hline $25-29$ & $16.4(15.5-17.3)$ & $17.2(16.4-17.9)$ & $15.8(14.8-17.0)$ \\
\hline $30-34$ & $14.1(13.4-15.0)$ & $13.5(12.8-14.2)$ & $15.8(14.7-17.0)$ \\
\hline $35-39$ & $13.1(12.3-13.9)$ & $13.0(12.3-13.7)$ & $12.5(11.6-13.5)$ \\
\hline $40-44$ & $9.5(8.8-10.2)$ & $9.8(9.2-10.4)$ & $9.4(8.6-10.4)$ \\
\hline $45-49$ & $8.5(7.9-9.2)$ & $8.7(8.2-9.3)$ & $6.9(6.2-7.7)$ \\
\hline \multicolumn{4}{|l|}{ Region } \\
\hline Morovia & $26.2(25.2-27.2)$ & - & $21.3(20.1-22.5)$ \\
\hline North Western & $10.8(10.1-11.5)$ & $16.9(16.1-17.6)$ & $12.2(11.2-13.2)$ \\
\hline South Central & $15.1(14.3-16.0)$ & $29.9(28.9-30.8)$ & $17.0(15.9-18.1)$ \\
\hline South Eastern A & $11.3(10.6-12.1)$ & $14.8(14.1-15.5)$ & $14.9(13.9-16.0)$ \\
\hline South Eastern B & $17.5(16.7-18.4)$ & $15.5(14.8-16.2)$ & $17.4(16.3-18.5)$ \\
\hline North Central & $19.0(18.2-20.0)$ & $23.0(22.2-23.9)$ & $17.3(16.2-18.5)$ \\
\hline \multicolumn{4}{|l|}{ Place of residence } \\
\hline Urban & $45.0(43.9-46.2)$ & $40.3(39.3-41.3)$ & $54.3(52.8-55.8)$ \\
\hline Rural & $55.0(53.8-56.1)$ & $59.7(58.7-60.7)$ & $45.7(44.2-47.2)$ \\
\hline \multicolumn{4}{|l|}{ Level of education } \\
\hline No education & $41.8(40.6-42.9)$ & $39.8(38.8-40.8)$ & $35.5(34.1-36.9)$ \\
\hline Primary & $35.0(33.9-36.1)$ & $34.6(33.6-35.6)$ & $27.6(26.3-29.0)$ \\
\hline Secondary & $21.6(20.6-22.6)$ & $23.4(22.6-24.3)$ & $32.8(31.4-34.2)$ \\
\hline Higher & $1.7(1.4-2.0)$ & $2.2(1.9-2.5)$ & $4.1(3.5-4.7)$ \\
\hline \multicolumn{4}{|l|}{ Religion } \\
\hline Christian & $87.1(86.3-87.9)$ & $85.2(84.4-85.9)$ & $87.9(86.9-88.8)$ \\
\hline Muslim & $9.9(9.2-10.6)$ & $11.9(11.2-12.6)$ & $10.4(9.5-11.4)$ \\
\hline Traditional & $0.4(0.3-0.6)$ & $0.4(0.3-0.5)$ & $0.4(0.2-0.6)$ \\
\hline Nil & $2.6(2.3-3.0)$ & $0.3(0.2-0.4)$ & $1.3(1.0-1.7)$ \\
\hline \multicolumn{4}{|l|}{ Sex of household head } \\
\hline Male & $64.8(63.7-65.9)$ & $63.8(62.8-64.7)$ & $66.2(64.7-67.6)$ \\
\hline Female & $35.2(34.1-36.3)$ & $36.2(35.3-37.2)$ & $33.8(32.4-35.3)$ \\
\hline Frequency of reading newspaper or magazine & & & No data \\
\hline Not at all & $77.2(76.2-78.2)$ & $84.6(83.9-85.4)$ & \\
\hline Less than once a week & $7.9(7.2-8.5)$ & $9.4(8.8-10.0)$ & \\
\hline At least once a week & $10.7(10.0-11.4)$ & $5.9(5.5-6.4)$ & \\
\hline Almost every day & $4.3(3.8-4.8)$ & - & \\
\hline Frequency of listening to radio & & & No data \\
\hline Not at all & $40.0(38.8-41.1)$ & $33.5(32.6-34.5)$ & \\
\hline Less than once a week & $11.2(10.4-11.9)$ & $31.4(30.5-32.4)$ & \\
\hline At least once a week & $22.2(21.3-23.2)$ & $35.1(34.1-36.1)$ & \\
\hline Almost every day & $26.7(25.6-27.7)$ & - & \\
\hline
\end{tabular}


Table 1 Characteristics of respondents, Liberia, 2007-2016 (Continued)

\begin{tabular}{|c|c|c|c|}
\hline Variable, \%(95\% Cl) & 2007 DHS $(n=7092)$ & 2013 DHS $(n=9239)$ & $2016 \operatorname{MIS}(n=4290)$ \\
\hline Frequency of watching television & & & No data \\
\hline Not at all & $61.6(60.4-62.7)$ & $73.5(72.6-74.4)$ & \\
\hline Less than once a week & $10.2(9.5-10.9)$ & $14.9(14.2-15.7)$ & \\
\hline At least once a week & $17.1(16.2-18.0)$ & $11.5(10.9-12.2)$ & \\
\hline Almost every day & $11.2(10.4-11.9)$ & - & \\
\hline \multicolumn{4}{|l|}{ Wealth index } \\
\hline Poorest & $19.0(18.1-19.9)$ & $28.0(27.1-28.9)$ & $23.5(22.2-24.8)$ \\
\hline Poorer & $19.5(18.6-20.4)$ & $24.7(23.8-25.6)$ & $18.7(17.6-19.9)$ \\
\hline Middle & $19.7(18.8-20.6)$ & $21.6(20.8-22.5)$ & $22.6(21.4-23.9)$ \\
\hline Richer & $22.1(21.1-23.0)$ & $14.1(13.4-14.9)$ & $18.3(17.1-19.4)$ \\
\hline Richest & $19.8(18.9-20.7)$ & $11.6(10.9-12.2)$ & $16.9(15.9-18.1)$ \\
\hline \multicolumn{4}{|l|}{ Children ever born } \\
\hline $1-4$ & $65.6(64.4-66.8)$ & $62.0(60.9-63.1)$ & $62.1(60.5-63.8)$ \\
\hline$>4$ & $34.4(33.2-35.6)$ & $38.0(36.9-39.1)$ & $37.9(36.2-39.5)$ \\
\hline
\end{tabular}

facility-based delivery seems to have improved better compared to adequate ANC visits among respondents.

\section{Factors associated with facility-based delivery}

The factors associated with facility-based delivery were examined using binary logistic regression in Table 2. There was significant increase in the odds of facility-based delivery in 2013 compared to $2007(\mathrm{OR}=2.21 ; 95 \% \mathrm{CI}=1.30$ $3.75)$. Women aged 20-24 and 25-29 years had significant reduction in the odds of facility-based delivery compared to younger women aged 15-19years. Regional diversity was associated with facility-based delivery, after adjusting for other covariates. In addition, rural women had 55\% reduction in the odds of facility-based delivery when compared to their urban counterpart $(\mathrm{OR}=0.45 ; 95 \%$ $\mathrm{CI}=0.31-0.65)$. Maternal education improved the utilization of facility-based delivery as educated women were found to have higher odds when compared to women with no formal education. More so, women with no religious affiliation had reduction in facilitybased delivery, compared to Christian women, after adjusting for other confounders. Households with female head had higher odds of facility-based delivery after controlling for other covariates $(\mathrm{OR}=1.20$; 95\% $\mathrm{CI}=1.07-1.36)$. The use of media specifically women who listen to radio significantly had increase in the

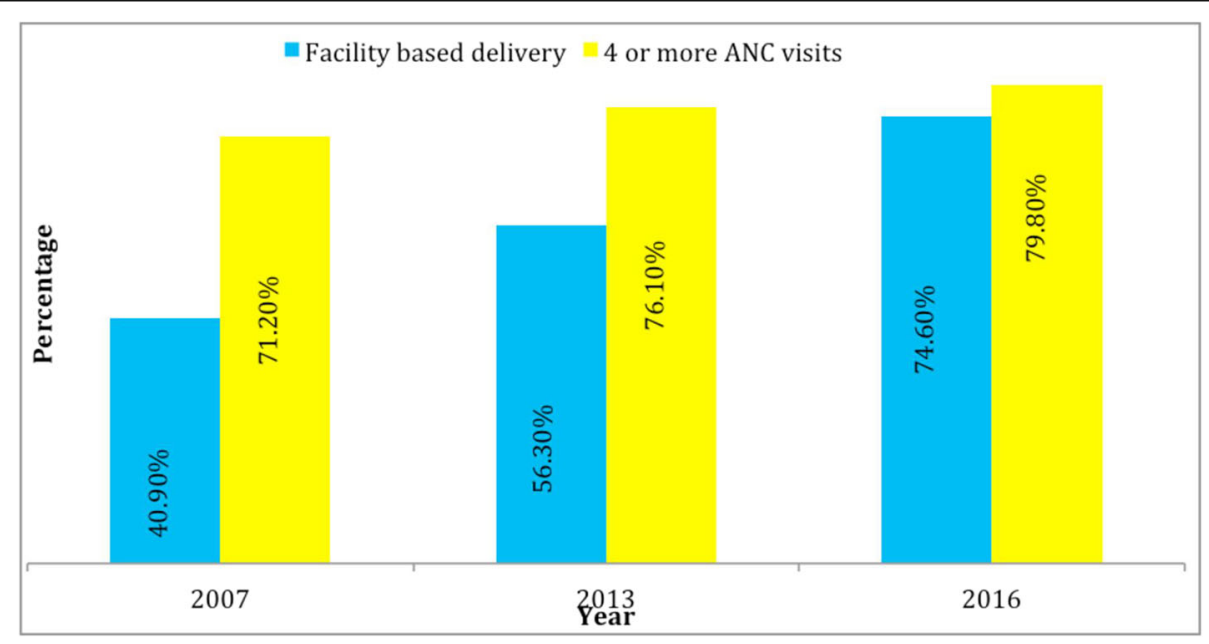

Fig. 1 Changes in maternal services utilization 2007-2016 
Table 2 Multivariable logistic regression model to examine factors associated with facility-based delivery in Liberia, 2007-2016

\begin{tabular}{|c|c|c|c|c|}
\hline Variable & Crude OR $(95 \% \mathrm{Cl})$ & $P$-value & Adjusted OR $(95 \% \mathrm{Cl})$ & $P$-value \\
\hline \multicolumn{5}{|l|}{ Year } \\
\hline 2007 & 1.00 & & 1.00 & \\
\hline 2013 & $1.86(1.51-2.29)$ & $<0.001^{*}$ & $2.21(1.30-3.75)$ & $0.003^{*}$ \\
\hline 2016 & $4.14(3.14-5.46)$ & $<0.001^{*}$ & $3.01(3.83-11.67)$ & 0.001 \\
\hline Age at first birth & 1.01 (0.99-1.03) & 0.096 & Ns & \\
\hline \multicolumn{5}{|l|}{ Age } \\
\hline $15-19$ & 1.00 & & 1.00 & \\
\hline $20-24$ & $0.86(0.73-1.01)$ & 0.053 & $0.81(0.67-0.99)$ & $0.045^{*}$ \\
\hline $25-29$ & $0.77(0.65-0.91)$ & $0.002^{*}$ & $0.79(0.63-0.98)$ & $0.034^{*}$ \\
\hline $30-34$ & $0.72(0.61-0.84)$ & $<0.001^{*}$ & $0.85(0.68-1.07)$ & 0.175 \\
\hline $35-39$ & $0.73(0.61-0.86)$ & $<0.001^{*}$ & $0.92(0.70-1.21)$ & 0.567 \\
\hline $40-44$ & $0.58(0.48-0.71)$ & $<0.001^{*}$ & $0.91(0.66-1.26)$ & 0.577 \\
\hline $45-49$ & $0.50(0.37-0.67)$ & $<0.001^{*}$ & $1.08(0.71-1.64)$ & 0.725 \\
\hline \multicolumn{5}{|l|}{ Region } \\
\hline Morovia & 1.00 & & 1.00 & \\
\hline North Western & $0.68(0.53-0.87)$ & $0.002^{*}$ & $0.76(0.56-1.05)$ & 0.094 \\
\hline South Central & $0.48(0.37-0.62)$ & $<0.001^{*}$ & $1.20(0.87-1.66)$ & 0.255 \\
\hline South Eastern A & $0.76(0.55-1.04)$ & 0.084 & $1.21(0.84-1.73)$ & 0.303 \\
\hline South Eastern B & $0.50(0.39-0.65)$ & $<0.001^{*}$ & $0.94(0.68-1.30)$ & 0.720 \\
\hline North Central & $0.33(0.23-0.48)$ & $<0.001^{*}$ & $1.65(1.04-2.61)$ & $0.034^{*}$ \\
\hline \multicolumn{5}{|l|}{ Place of residence } \\
\hline Urban & 1.00 & & 1.00 & \\
\hline Rural & $0.32(0.27-0.39)$ & $<0.001^{*}$ & $0.45(0.31-0.65)$ & $<0.001^{*}$ \\
\hline \multicolumn{5}{|l|}{ Level of education } \\
\hline No education & 1.00 & & 1.00 & \\
\hline Primary & $1.41(1.26-1.59)$ & $<0.001^{*}$ & $1.11(0.96-1.27)$ & 0.150 \\
\hline Secondary & $3.35(2.88-3.89)$ & $<0.001^{*}$ & $1.45(1.20-1.76)$ & $<0.001^{*}$ \\
\hline Higher & $11.32(6.85-18.69)$ & $<0.001^{*}$ & $3.72(1.82-7.61)$ & $<0.001^{*}$ \\
\hline \multicolumn{5}{|l|}{ Religion } \\
\hline Christian & 1.00 & & 1.00 & \\
\hline Muslim & $0.97(0.78-1.21)$ & 0.774 & $1.06(0.78-1.44)$ & 0.697 \\
\hline Traditional & $0.85(0.45-1.60)$ & 0.614 & $1.54(0.63-3.82)$ & 0.345 \\
\hline Nil & $0.41(0.28-0.59)$ & $<0.001^{*}$ & $0.55(0.35-0.85)$ & $0.007^{*}$ \\
\hline \multicolumn{5}{|l|}{ Sex of household head } \\
\hline Male & 1.00 & & 1.00 & \\
\hline Female & $1.40(1.25-1.56)$ & $<0.001^{*}$ & $1.20(1.07-1.36)$ & $0.003^{*}$ \\
\hline \multicolumn{5}{|c|}{ Frequency of reading newspaper or magazine } \\
\hline Not at all & 1.00 & & 1.00 & \\
\hline Less than once a week & $2.57(2.00-3.31)$ & $<0.001^{*}$ & $1.01(0.77-1.31)$ & 0.951 \\
\hline At least once a week & $2.93(2.28-3.78)$ & $<0.001^{*}$ & $1.17(0.85-1.60)$ & 0.335 \\
\hline Almost every day & $4.76(2.64-8.60)$ & $<0.001^{*}$ & $0.99(0.49-1.99)$ & 0.979 \\
\hline \multicolumn{5}{|l|}{ Frequency of listening to radio } \\
\hline Not at all & 1.00 & & 1.00 & \\
\hline Less than once a week & $2.18(1.85-2.57)$ & $<0.001^{*}$ & $1.24(1.04-1.48)$ & $0.016^{*}$ \\
\hline
\end{tabular}


Table 2 Multivariable logistic regression model to examine factors associated with facility-based delivery in Liberia, 2007-2016 (Continued)

\begin{tabular}{|c|c|c|c|c|}
\hline Variable & Crude OR (95\% Cl) & $P$-value & Adjusted OR (95\% Cl) & $P$-value \\
\hline At least once a week & $2.09(1.78-2.46)$ & $<0.001^{*}$ & $1.12(0.95-1.32)$ & 0.165 \\
\hline Almost every day & 2. $(2.31-3.67)$ & $<0.001^{*}$ & $1.61(1.24-2.10)$ & $<0.001^{*}$ \\
\hline \multicolumn{5}{|c|}{ Frequency of watching television } \\
\hline Not at all & 1.00 & & 1.00 & \\
\hline Less than once a week & $2.02(1.67-2.43)$ & $<0.001^{*}$ & $0.96(0.79-1.17)$ & 0.684 \\
\hline At least once a week & $2.22(1.77-2.79)$ & $<0.001^{*}$ & $1.06(0.83-1.35)$ & 0.626 \\
\hline Almost every day & $3.16(2.29-4.35)$ & $<0.001^{*}$ & $1.31(0.92-1.87)$ & 0.133 \\
\hline \multicolumn{5}{|l|}{ Wealth index } \\
\hline Poorest & 1.00 & & 1.00 & \\
\hline Poorer & $1.40(1.18-1.66)$ & $<0.001^{*}$ & $1.12(0.81-1.53)$ & 0.501 \\
\hline Middle & $1.91(1.58-2.32)$ & $<0.001^{*}$ & $1.52(1.02-2.26)$ & $0.039^{*}$ \\
\hline Richer & $3.16(2.54-3.91)$ & $<0.001^{*}$ & $2.48(1.60-3.85)$ & $<0.001^{*}$ \\
\hline Richest & $5.35(4.09-7.00)$ & $<0.001^{*}$ & $2.72(1.66-4.46)$ & $<0.001^{*}$ \\
\hline \multicolumn{5}{|l|}{ Children ever born } \\
\hline $1-4$ & 1.00 & & 1.00 & \\
\hline$>4$ & $0.65(0.58-0.71)$ & $<0.001^{*}$ & $0.85(0.71-1.01)$ & 0.080 \\
\hline \multicolumn{5}{|l|}{ Antenatal care visits } \\
\hline$<4$ & 1.00 & & 1.00 & \\
\hline 4 and above & $3.62(3.16-4.14)$ & $<0.001^{*}$ & $2.90(2.52-3.36)$ & $<0.001^{*}$ \\
\hline \multicolumn{5}{|l|}{ Year*Residence } \\
\hline $2007 *$ Urban & 1.00 & & 1.00 & \\
\hline $2013^{*}$ Rural & $2.17(1.44-3.25)$ & $<0.001^{*}$ & $1.64(1.01-2.67)$ & $0.047^{*}$ \\
\hline $2016 *$ Rural & $2.95(1.74-4.99)$ & $<0.001^{*}$ & & \\
\hline \multicolumn{5}{|l|}{ Year*wealth index } \\
\hline 2007 Poorest & 1.00 & & 1.00 & \\
\hline 2013*Poorer & $0.98(0.68-1.41)$ & 0.914 & $1.09(0.75-1.59)$ & 0.643 \\
\hline 2013*Middle & $0.77(0.49-1.23)$ & 0.276 & $0.94(0.59-1.49)$ & 0.784 \\
\hline 2013*Richer & $0.54(0.32-0.90)$ & $0.018^{*}$ & $0.82(0.47-1.43)$ & 0.481 \\
\hline 2013*Richest & $0.58(0.29-1.16)$ & 0.121 & $1.18(0.56-2.49)$ & 0.658 \\
\hline 2016*Poorer & $1.48(0.85-2.55)$ & 0.164 & & \\
\hline 2016*Middle & $0.77(0.41-1.43)$ & 0.401 & & \\
\hline 2016*Richer & $0.37(0.19-0.71)$ & $0.003^{*}$ & & \\
\hline 2016*Richest & $0.27(0.13-0.56)$ & $<0.001^{*}$ & & \\
\hline
\end{tabular}

${ }^{*}$ significant at $p<0.05$

Mckelvey and Zavoina's R2 $=0.992$

odds of facility-based delivery compared to women who do not listen to radio; women who listen to radio almost every day were 1.61 times as likely to utilize facility-based delivery compared to non-listeners $(\mathrm{OR}=1.61 ; 95 \% \mathrm{CI}=1.38-2.02)$; for those who watch television almost every day $(\mathrm{OR}=1.41 ; 95 \%$ $\mathrm{CI}=1.24-2.10)$. Women with middle, richer and richest wealth index had significant increase in the odds of facility-based delivery when compared to poorest women, after adjusting for other covariates. Antenatal care (ANC) visits was significantly associated with facility-based delivery; women who reported at least 4 ANC visits were 2.90 times as likely to utilize facility-based delivery, compared to women who reported less than ANC visits $(\mathrm{OR}=$ $2.90 ; 95 \% \mathrm{CI}=2.52-3.36$ ). Further results showed the 
interaction between year and place of residence; respondents from year 2013 and rural residence were 1.64 times as likely to utilize facility-based delivery compared to respondents from 2007 and in urban residence. See Table 2 for details.

\section{Determinants of antenatal care visits}

The results showed increase in antenatal care visits over the period of study. For geographical division, women from South Eastern A had 39\% significant reduction in adequate ANC when compared to Morovia. There was $49 \%$ significant reduction in ANC visits among rural women, compared to women from urban residence after adjusting for other covariates $(\mathrm{OR}=0.51 ; 95 \% \mathrm{CI}=0.36-0.72)$.

Women with formal education had significant higher odds of adequate antenatal visits compared to those with no formal education. In addition, religious belief was significantly associated with antenatal care visits; women of Islamic belief were 1.90 times as likely to have adequate $\mathrm{ANC}$ when compared to the Christian women $(\mathrm{OR}=1.90 ; 95 \% \mathrm{CI}=1.38-2.61)$. Women who use of media such as listening to radio had higher odds of adequate antenatal care visits, compared to those who do not listen to radio. More so, wealth index was significantly associated with antenatal care utilization; women from richest households were 3.04 times as likely to utilize adequate antenatal care visits compared to women from poorest households $(\mathrm{OR}=3.04 ; 95 \% \mathrm{CI}=$ 1.75-5.29). Further, there was interaction between year and place of residence; respondents from year 2013 and rural residence were 1.83 times as likely to utilize adequate ANC visits compared to respondents from 2007 and urban after adjusting for other covariates. See Table 3 for details.

\section{Discussion}

This paper explored the changes in maternal services utilization and associated factors with ANC visits and facility-based delivery in post-war era in Liberia. The results of the study implied a level of progress in maternal health care including adequate ANC visits and facilitybased delivery in Liberia between 2007 and 2016. The progress in adequate ANC visits does not match the improvement in facility-based delivery during the study period. Whereas an improvement in the utilization of maternal healthcare could be expected over time, especially in the post-war era, significant increase in adequate ANC visits was not observed during the study period. A major explanation could be the prolonged period and nature of the war which ended after 14 years of displacement, the system might not yet recover to the expected level of full functionality. In our findings, initial percentage of maternal care utilization was low, but with a steady increase in skilled care for women between 2007 and 2016. This is in line with the reports of a previous study $[8,24]$.

This study has provided vast comprehensive findings in the effect of war on maternal health care services utilization in Liberia, and an in-depth association in factors associated with maternal health. Furthermore, the level of maternal health care utilization found among rural respondents and other disadvantaged groups was worrisome during the study period. The trend was consistent in prenatal care and facility-based delivery, and this finding is comparable to other studies [25]. More so, the results showed that the use of media enhanced utilization of maternal health care services. The media specifically listening to radio could help to improve the level of awareness and behavior change communication especially in rural areas, thereby making women more informed about health care intervention programmes set to improve women's attitude towards health care services during antenatal and intrapartum care [26, 27].

Several factors were identified to be associated with maternal health care services. Good educational background, urban residence and high wealth index were among the factors identified to increase maternal health care utilization. Education was found to have positive correlation with ANC visits and facility-based delivery. This means that women with good educational background had better maternal health care utilization. This implies that knowledge about the use of ANC visits and institutional delivery could be obtained through education. A previous study has reported that the increase in female literacy was associated with a decline in maternal mortality [28]. Notwithstanding, there are other moderators that could help to aggravate access to behavior change communication. In addition, economic status of women can affect the health-care seeking behaviour in resource constrained setting, such as Liberia. In this study, wealth inequity was a major factor identified in maternal health care utilization. There was a consistent finding of respondents with high wealth index having higher chance of adequate ANC visits and institutional delivery [29-32].

Another factor identified within the study period was the geographical region and place of residence, with urban women having higher odds of facilitybased delivery and adequate antenatal care; these findings are consistent with previous studies [32-36]. For maternal services utilization, the study found significant interactions between study year, wealth status and place of residence. Women in a more 
Table 3 Multivariable logistic regression model to examine factors associated with adequate antenatal visits in Liberia, 2007-2016

\begin{tabular}{|c|c|c|c|c|}
\hline Variable & Crude OR $(95 \%$ Cl) & $P$-value & Adjusted OR (95\% Cl) & $P$-value \\
\hline \multicolumn{5}{|l|}{ Year } \\
\hline 2007 & 1.00 & - & 1.00 & - \\
\hline 2013 & $1.30(1.07-1.59)$ & $0.010^{*}$ & $0.86(0.53-1.39)$ & 0.537 \\
\hline 2016 & $1.51(1.16-1.95)$ & $0.002^{*}$ & - & - \\
\hline Age at first birth & $1.01(0.99-1.03)$ & 0.415 & Ns & - \\
\hline \multicolumn{5}{|l|}{ Age } \\
\hline $15-19$ & 1.00 & & Ns & \\
\hline $20-24$ & $1.06(0.88-1.28)$ & 0.532 & Ns & \\
\hline $25-29$ & $1.05(0.87-1.27)$ & 0.590 & Ns & \\
\hline $30-34$ & $0.95(0.79-1.17)$ & 0.676 & Ns & \\
\hline $35-39$ & $1.16(0.94-1.42)$ & 0.173 & Ns & \\
\hline $40-44$ & $0.85(0.67-1.08)$ & 0.196 & Ns & \\
\hline $45-49$ & $0.78(0.55-1.12)$ & 0.179 & Ns & \\
\hline \multicolumn{5}{|l|}{ Region } \\
\hline Morovia & 1.00 & & 1.00 & \\
\hline North Western & $0.73(0.56-0.96)$ & 0.023 & $0.95(0.69-1.31)$ & 0.765 \\
\hline South Central & $0.54(0.41-0.73)$ & $<0.001^{*}$ & $1.34(0.97-1.86)$ & 0.080 \\
\hline South Eastern A & $0.41(0.31-0.54)$ & $<0.001^{*}$ & $0.61(0.43-0.86)$ & $0.005^{*}$ \\
\hline South Eastern B & $0.51(0.39-0.66)$ & $<0.001^{*}$ & $1.06(0.77-1.47)$ & 0.717 \\
\hline North Central & $0.41(0.28-0.58)$ & $<0.001^{*}$ & $1.18(0.76-1.82)$ & 0.456 \\
\hline \multicolumn{5}{|l|}{ Place of residence } \\
\hline Urban & 1.00 & & 1.00 & \\
\hline Rural & $0.41(0.35-0.49)$ & $<0.001^{*}$ & $0.51(0.36-0.72)$ & $<0.001^{*}$ \\
\hline \multicolumn{5}{|l|}{ Level of education } \\
\hline No education & 1.00 & & 1.00 & \\
\hline Primary & $1.33(1.17-1.50)$ & $<0.001^{*}$ & $1.28(1.11-1.48)$ & $0.001^{*}$ \\
\hline Secondary & $2.49(2.10-2.95)$ & $<0.001^{*}$ & $1.63(1.27-2.09)$ & $<0.001^{*}$ \\
\hline Higher & $7.01(3.58-13.71)$ & $<0.001^{*}$ & $4.33(1.50-12.55)$ & $0.007^{*}$ \\
\hline \multicolumn{5}{|l|}{ Religion } \\
\hline Christian & 1.00 & & 1.00 & \\
\hline Muslim & $1.76(1.34-2.32)$ & $<0.001^{*}$ & $1.90(1.38-2.61)$ & $<0.001^{*}$ \\
\hline Traditional & $0.68(0.32-1.42)$ & 0.301 & $1.21(0.57-2.59)$ & 0.617 \\
\hline Nil & $0.57(0.39-0.81)$ & $0.002^{*}$ & $0.78(0.52-1.16)$ & 0.217 \\
\hline \multicolumn{5}{|l|}{ Sex of household head } \\
\hline Male & 1.00 & & 1.00 & \\
\hline Female & $1.24(1.08-1.41)$ & $0.002^{*}$ & $1.13(0.98-1.30)$ & 0.091 \\
\hline \multicolumn{5}{|c|}{ Frequency of reading newspaper or magazine } \\
\hline Not at all & 1.00 & & 1.00 & \\
\hline Less than once a week & $2.38(1.72-3.30)$ & $<0.001^{*}$ & $1.04(0.74-1.48)$ & 0.812 \\
\hline At least once a week & $2.30(1.67-3.18)$ & $<0.001^{*}$ & $0.99(0.69-1.45)$ & 0.990 \\
\hline Almost every day & $7.10(1.50-33.65)$ & $<0.001^{*}$ & $1.37(0.27-6.94)$ & 0.700 \\
\hline \multicolumn{5}{|c|}{ Frequency of listening to radio } \\
\hline Not at all & 1.00 & & 1.00 & \\
\hline Less than once a week & $2.03(1.67-2.46)$ & $<0.001^{*}$ & $1.33(1.09-1.62)$ & $0.005^{*}$ \\
\hline
\end{tabular}


Table 3 Multivariable logistic regression model to examine factors associated with adequate antenatal visits in Liberia, 2007-2016 (Continued)

\begin{tabular}{|c|c|c|c|c|}
\hline Variable & Crude OR (95\% Cl) & $P$-value & Adjusted OR (95\% Cl) & $P$-value \\
\hline At least once a week & $1.70(1.44-2.02)$ & $<0.001^{*}$ & $1.09(0.90-1.31)$ & 0.366 \\
\hline Almost every day & $2.92(2.23-3.83)$ & $<0.001^{*}$ & $1.64(1.18-2.27)$ & $0.003^{*}$ \\
\hline \multicolumn{5}{|c|}{ Frequency of watching television } \\
\hline Not at all & 1.00 & & 1.00 & \\
\hline Less than once a week & $2.26(1.79-2.85)$ & $<0.001^{*}$ & $1.32(1.04-1.67)$ & 0.024 \\
\hline At least once a week & $1.95(1.55-2.46)$ & $<0.001^{*}$ & $1.04(0.81-1.32)$ & 0.769 \\
\hline Almost every day & $3.07(1.99-4.74)$ & $<0.001^{*}$ & $1.10(0.68-1.79)$ & 0.696 \\
\hline \multicolumn{5}{|l|}{ Wealth index } \\
\hline Poorest & 1.00 & & 1.00 & \\
\hline Poorer & $1.38(1.16-1.64)$ & $<0.001^{*}$ & $1.11(0.81-1.53)$ & 0.514 \\
\hline Middle & $2.25(1.86-2.72)$ & $<0.001^{*}$ & $1.54(1.11-1.85)$ & $0.010^{*}$ \\
\hline Richer & $3.11(2.51-3.85)$ & $<0.001^{*}$ & $2.06(1.36-3.12)$ & $0.001^{*}$ \\
\hline Richest & $5.18(3.85-6.95)$ & $<0.001^{*}$ & $3.04(1.75-5.29)$ & $<0.001^{*}$ \\
\hline \multicolumn{5}{|l|}{ Children ever born } \\
\hline $1-4$ & 1.00 & & 1.00 & \\
\hline$>4$ & $0.77(0.69-0.87)$ & $<0.001^{*}$ & $1.02(0.89-1.17)$ & 0.758 \\
\hline \multicolumn{5}{|l|}{ Year*Residence } \\
\hline $2007^{*}$ Urban & 1.00 & & 1.00 & \\
\hline $2013^{*}$ Rural & $2.03(1.4-2.95)$ & $<0.001^{*}$ & $1.83(1.21-2.75)$ & $0.004^{*}$ \\
\hline $2016^{*}$ Rural & $2.39(1.47-3.87)$ & $<0.001^{*}$ & & \\
\hline \multicolumn{5}{|l|}{ Year*wealth index } \\
\hline $2007 *$ Urban & 1.00 & & & \\
\hline 2013*Poorer & $1.11(0.76-1.63)$ & 0.579 & $1.13(0.76-1.68)$ & 0.560 \\
\hline 2013*Middle & $0.99(0.65-1.52)$ & 0.969 & $1.19(0.77-1.85)$ & 0.421 \\
\hline 2013*Richer & $0.80(0.50-1.29)$ & 0.368 & $1.15(0.67-1.98)$ & 0.613 \\
\hline 2013*Richest & $0.47(0.23-0.94)$ & $0.033^{*}$ & $0.79(0.36-1.72)$ & 0.554 \\
\hline 2016*Poorer & $1.51(0.85-2.67)$ & 0.162 & $1.47(0.85-2.55)$ & 0.164 \\
\hline 2016*Middle & $1.16(0.63-2.16)$ & 0.628 & $0.76(0.41-1.42)$ & 0.401 \\
\hline 2016*Richer & $0.48(0.26-0.89)$ & $0.019^{*}$ & $0.36(0.19-0.71)$ & $0.003^{*}$ \\
\hline 2016*Richest & $0.40(0.18-0.85)$ & $0.018^{*}$ & $0.26(0.12-0.56)$ & $0.000^{*}$ \\
\hline
\end{tabular}

*significant at $p<0.05$

Mckelvey and Zavoina's R2 $=0.987$

recent study year, though living in rural settings had higher services utilization, which could be due to increase in awareness and other interventions in improving maternal services utilization. Attendance at ANC was shown to be associated with healthcare facility delivery. Adequacy in antenatal care visits increased the utilization of facility-based delivery, as women who attended four or more ANC visits were more likely to deliver at a healthcare facility, which is consistent with previous studies [37, 38]. ANC visits provide the opportunity to give health messages which could result in better understanding and compliance by the women to utilize skilled birth attendance.

\section{Strengths and limitations}

This study utilized multiple national datasets from two different bodies, and over a period of 10 years to establish the significant pattern or trend in maternal health care in post-war era. The sample size collected from three rounds of surveys was sufficiently large and by standard procedure which increases the external validity of the findings for women aged between 
15 to 49 years in Liberia. However cross-sectional study data are inadequate to establish causality. Again, the self-reported data can be subject to recall bias among the respondents $[39,40]$.

\section{Conclusion}

Though there was an improvement in formal institutional delivery and recommended ANC attendance between 2007 and 2016, the proportions are still below the global coverage target. Particularly, the utilization varied across regions, rural-urban, maternal educational level, sex of household head, media access and wealth index. We, therefore, emphasize the need for strengthening and replication of the demand and supply side interventions if the ambitious global targets of reducing neonatal mortality, maternal mortality and stillbirths are to be achieved.

\section{Abbreviations}

ANC: Antenatal care; DHS: Demographic health survey; IRB: Institutional review board; MCIS: Multiple indicator cluster survey; MMR: Maternal mortality ratio; NDS: National drug service; RMNCAH: Reproductive, maternal, newborn, child, and adolescent health; SDGs: Sustainable development goals

\section{Acknowledgments}

The authors thank the MEASURE DHS project for their support and for free access to the original data.

\section{Funding}

The authors have no support or funding to report.

\section{Availability of data and materials}

Data for this study were sourced from the Liberia Demographic and Health surveys (DHS) and available here: https://dhsprogram.com/what-we-do/ survey/survey-display-271.cfm and here https://dhsprogram.com/what-wedo/survey/survey-display-435.cfm

\section{Authors' contributions}

SY and ME contributed to the study design, the review of literature, and analysis of literature, manuscript conceptualisation and preparation. OU and GB critically reviewed the manuscript for its intellectual content. SY had final responsibility to submit for publication. All authors read and approved the final manuscript.

\section{Ethics approval and consent to participate}

Ethics approval for this study was not required since the data is secondary and is available in the public domain. More details regarding DHS data and ethical standards are available at: http://goo.gl/ny8T6X.

\section{Consent for publication}

Not applicable.

\section{Competing interests}

Sanni Yaya, Olalekan A Uthman and Ghose Bishwajit are member of the editorial board of this journal.

\section{Publisher's Note}

Springer Nature remains neutral with regard to jurisdictional claims in published maps and institutional affiliations.

\section{Author details}

${ }^{1}$ School of International Development and Global Studies, University of Ottawa, Ottawa, Canada. ${ }^{2}$ Warwick Centre for Applied Health Research and Delivery (WCAHRD), Division of Health Sciences, Warwick Medical School, University of Warwick, Coventry CV4 7AL, UK. ${ }^{3}$ Department of Epidemiology and Medical Statistics, Faculty of Public Health, College of Medicine, University of Ibadan, Ibadan, Nigeria.

Received: 15 June 2018 Accepted: 21 December 2018

Published online: 08 January 2019

\section{References}

1. Alkema L, Chou D, Hogan D, Zhang S, Moller A, Gemmill A, et al. Global, Regional, and National Levels and Trends in Maternal Mortality between 1990 and 2015, with Scenario Based Projections to 2030. In: A Systematic Analysis by The UN Maternal Mortality Estimation Inter Agency Group, vol. 6736; 2015. p. 1-13.

2. Bhutta ZA, Black RE. Global maternal, newborn, and child health-so near and yet so far. N Engl J Med. 2013;369(23):2226-35.

3. World Health Organization. Trends in maternal mortality: 1990-2010. Geneva: WHO. p. 2012

4. Johnson K, Asher J, Rosborough S, et al. Association of combatant status and sexual violence with health and mental health outcomes in postconflict Liberia. J Am Med Assoc. 2008;300:676.

5. Svoronos T, Macauley RJ, Kruk ME. Can the health system deliver? Determinants of rural Liberians' confidence in health care. Health Policy Plan. 2015:30:823-9.

6. WHO. Global Health Observatory, Liberia Health System. Geneva: WHO; 2016.

7. Liberia, Demographic and Health Survey. 2013. Liberia Institute of Statistics and Geo-Information Services (LISGIS). Monrovia, Liberia. Ministry of Health and Social Welfare [Liberia], National Aids Control Program [Liberia], and ICF International. 2014. Liberia Demographic and Health Survey 2013. Liberia Institute of Statistics and Geo-Information Services (LISGIS) and ICF International. https://dhsprogram.com/pubs/pdf/FR291/FR291.pdf. Accessed 17 Feb 2018.

8. Kentoffio K, Kraemer JD. Griffiths T et al. Charting health system reconstruction in post-war Liberia: a comparison of rural vs remote healthcare utilization BMC Health Services Research. 2016:16:478.

9. Republic of Liberia. Investment Case for Reproductive, Maternal, New-Born, Child, and Adolescent Health 2016-2020. p17. Retrieved on 27/12/2017 from http://globalfinancingfacility.org/sites/gff_new/files/documents/ Liberia\%20RMNCAH\%20Investment\%20Case\%202016\%20-\%202020.pdf. Accessed 17 Feb 2018

10. Loevinsohn B, Harding A. Buying results? Contracting for health service delivery in developing countries. Lancet. 2005;366(9486):676-81.

11. Liberian Ministry of Health and Social Welfare. National Health Policy/National Health Plan. Monrovia, Liberia: 2007. http://apps.who.int/medicinedocs/ documents/s18363en/s18363en.pdf. [Accessed 17 Feb 2018].

12. Roberts B, Guy S, Sondorp E, Lee-Jones L. A basic package of health services for post-conflict countries: implications for sexual and reproductive health services. Reprod Health Matters. 2008;16(31):57-64.

13. Cometto G, Fritsche $\mathrm{G}$, Sondorp E. Health sector recovery in early post-conflict environments: experience from southern Sudan. Disasters. 2010;34(4):885-909.

14. Peters DH, Noor AA, Singh LP, Kakar FK, Hansen PM. A balanced scorecard for health services in Afghanistan. Bull World Health Organ. 2007:85(2):146-51.

15. Hansen PM, Peters DH, Nayesh H, Singh LP, Dwivedi V, Burnham G. Measuring and managing progress in the establishment of basic health services: the Afghanistan health sector balanced scorecard. Int J Health Plann Manag. 2008;23:107-17.

16. World Health Organization: Liberia country profile. 2007 [https://www.who. int/countries/lbr/en/ maternal_child_adolescent/countries/lib.pdf].

17. United Nations. Transforming our world: the 2030 agenda for sustainable development. New York: United Nations, Department of Economic and Social Affairs. 2015. Available at: https://sustainabledevelopment.un.org/ post2015/transformingourworld [Accessed February 17, 2018].

18. Ministry of Health and Social Welfare: Strategy for national in-service education. 2009 [http://liberiamohsw.org/Policies\%20\&\%20Plans/ National\%20In\%20Service\%20Education\%20Strategy.docx EducationProgram_Liberia.pdf].

19. Liberia Multiple Indicator Cluster Survey. United Nations Children's Fund (UNICEF); United Nations Population Fund (UNFPA). 2016.

20. Ejembi CL, Dahiru T. Aliyu AA. Contextual Factors Influencing Modern Contraceptive Use in Nigeria Demographic And Health Surveys. 2015;120.

21. Rutstein $\mathrm{S}$, Johnson $\mathrm{K}$. The DHS wealth index. DHS comparative reports no. 6. Calverton, Maryland: ORC Macro; 2004. 
22. Midi H, Sarkar SK, Rana S. Collinearity diagnostics of binary logistic regression model. J Interdisciplinary Math. 2010;13(3):253-67.

23. Theil H. The Assessment of Fit in the Class of Logistic Regression Models: A Pathway out of the Jungle of Pseudo-R2s Using Stata. 23. https:/Www.stata. com/meeting/germany16/slides/de16_langer.pdf. [Accessed 29 Mar 2018].

24. Bornemisza O, Ranson K, Poletti TH, Sondorp E. Promoting health equity in conflict-affected fragile states. Soc Sci Med. 2009;70(1):80-8.

25. Yaya S, Bishwajit $\mathrm{G}$, Ekholuenetale $\mathrm{M}$, et al. Urban-rural difference in satisfaction with primary healthcare services in Ghana. BMC Health Serv Res. 2017;17:776. https://doi.org/10.1186/s12913-017-2745-7.

26. Ahmed S, Khan MM. Is demand-side financing equity enhancing? Lessons from a maternal health voucher scheme in Bangladesh. Soc Sci Med. 2011;

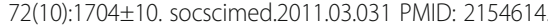

27. Yaya $\mathrm{S}$, Bishwajit $\mathrm{G}$, Ekholuenetale M. Factors associated with the utilization of institutional delivery services in Bangladesh. PLoS One. 2017;12(2): e0171573. https://doi.org/10.1371/journal.pone.017157320.

28. Mahbub Elahi C, Anisuddin A, Nahid K, Marge K. Causes of maternal mortality decline in Matlab, Bangladesh J Health Popul Nutr 2009;27:108123. PMID:19489410

29. Yaya S, Bishwajit G, Ekholuenetale M, Shah V, Kadio B, Udenigwe O. Timing and adequate attendance of antenatal care visits among women in Ethiopia. PLoS One. 2017:12(9):e0184934 https://doi.org/10.1371/journal.pone.0184934.

30. Bbaale E. Factors influencing timing and frequency of antenatal care in Uganda. Australasian Medical Journal. 2011:4(8):431-438. https://doi.org/10. 4066/AMJ. 2011.729 PMID: 23393530.

31. Gupta S, Yamada G, Mpembeni R, Frumence G, Callaghan-Koru JA Stevenson R, et al. Factors Associated with Four or More Antenatal Care Visits and Its Decline among Pregnant Women in Tanzania between 1999 and 2010. PLoS ONE. 2014;9(7):e101893. https://doi.org/10.1371/journal. pone.0101893.

32. Magadi MA, Agwanda AO, Obare FO. A comparative analysis of the use of maternal health services between teenagers and older mothers in subSaharan Africa: evidence from Demographic and Health Surveys (DHS). Soc Sci Med. $2007 ; 64(6): 131125$. PubMed PMID:17174017

33. Aa I, Grove MA, Haugsja AH, Hinderaker SG. High maternal mortality estimated by the sisterhood method in a rural area of Mali. BMC Pregnancy Childbirth. 2011;11:56.

34. Amin R, Shah M, Becker S. Socioeconomic factors differentiating maternal and child health-seeking behavior in rural Bangladesh: a cross-sectional analysis. Int J Equity Health. 2010;9:9.

35. Babalola S, Fatusi A. Determinants of use of maternal health services in Nigeria: looking beyond individual and household factors. BMC Pregnancy Childbirth. 2009;9:43.

36. Celik Y, Hotchkiss DR. The socio-economic determinants of maternal health care utilization in Turkey. Soc Sci Med. 2000;50:1797-806.

37. Gabrysch S, Campbell OM. Still too far to walk: literature review of the determinants of delivery senvice use. BMC Pregnancy and Childbirth. 2009;9(1):1.

38. Egharevba J, Pharr J, van Wyk B, Ezeanolue E. Factors influencing the choice of child delivery location among women attending antenatal care services and immunization Clinic in Southeastern Nigeria. Int J MCH \& AIDS. 2017; 6(1):82-92.

39. Yaya S, Ekholuenetale M, Bishwajit G. Differentials in prevalence and correlates of metabolic risk factors of non-communicable diseases among women in sub-Saharan Africa: evidence from 33 countries. BMC Public Health. 2018 Oct 11;18(1):1168. https://doi.org/10.1186/s12889-018-6085-2.

40. Yaya S, Uthman OA, Amouzou A, Bishwajit G. Disparities in caesarean section prevalence and determinants across sub-Saharan Africa countries. Global health research and policy. 2018;3:19. https://doi.org/10.1186/s41256018-0074-y eCollection 2018.

Ready to submit your research? Choose BMC and benefit from:
- fast, convenient online submission
- thorough peer review by experienced researchers in your field
- rapid publication on acceptance
- support for research data, including large and complex data types
- gold Open Access which fosters wider collaboration and increased citations
- maximum visibility for your research: over 100M website views per year
At BMC, research is always in progress.
Learn more biomedcentral.com/submissions

